$10^{-7}$ мм. рт.ст. В результате при установке на катоде рабочей температуры $950{ }^{\circ} \mathrm{C}$ и подаче анодного напряжения 500 В на аноде появился нестабильный ток, принимавший значения до 0,3 мА. Потом катод активировался собственным токопрохождением при температуре $950{ }^{\circ} \mathrm{C}$ с уровнем вакуума не ниже $10^{-7}$ мм. рт. ст в течение 40 минут, пока его ток не стабилизировался на значении 0,94 мА при анодном напряжении 1,5 кВ. Процесс активировки был закончен.

После активировки катод вновь стал давать стабильную термоэмиссию величиной 0,94 мА сначала при номинальном значении мощности накала катода 5,3 Вт, а потом при пониженной мощности накала катода 3,7 Вт.

Проверка стабильности эмиссионной способности катода в режиме пониженной мощности накала при Рнакала $=3,7$ Вт проходила 8 часов, эмиссионная способность катода не изменилась.

Вывод: В данном эксперименте была исследована работа импрегнированного вольфрамо-бариевого катода косвенного накала в недокалённом режиме. В ходе эксперимента были сняты вольт-амперные характеристики данного катода при мощностях накала катода: 3,7 Вт, 3,0 Вт, 2,5 Вт. Была обнаружена стабильная термоэлектронная эмиссия с катода при мощности накала подогревателя катода 3,7 Вт. В данном рабочем режиме экспериментальный макет проработал 8 часов. Можно сделать вывод, что в режиме пониженной мощности накала до Рнакала $=3,7$ Втвозможно обеспечение стабильной термоэлектронной эмиссии с катода.

В результате эксперимента было выяснено, что рабочую мощность накала катода можно снизить на $30 \%$ от первоначальной с сохранением необходимой эмиссионной способности катода.

В будущем планируется продолжение исследования работы импрегнированного вольфрамо-бариевого катода в режимах пониженного накала. В частности, будет проведено более детальное изучение работы данного катода в диапазоне мощности накала катода Рнакала $=3,0 \div 5,3$ Вт с более длительным временем нахождения в каждой точке мощности накала катода. Таким образом, допустимое снижение мощности накала катода будет установлено более точно.

$$
* * *
$$

1. Кудинцева Г.А., Мельников А.И., Морозов А.В., Никонов Б.П. Термоэлектронные катоды // Москва Ленинград : Энергия, 1966.

\title{
Хвалев П.С. \\ Идентификация потенциальных опасностей, как один из этапов методики анализа рисков обрушений мостовых сооружений
}

Оренбургский государственный университет (Россия, Оренбург)

doi: $10.18411 / \mathrm{j}-30-09-2017-28$

idsp: 000001:lj-30-09-2017-28

\section{Аннотация}

Целью анализа рисков мостовых переходов является повышение эффективности управления техническим состоянием для обеспечения охраны здоровья людей и их безопасности, предотвращения экономических и других потерь.

Современный период развития характеризуется, наряду с другими прогрессивными факторами и тем, что методы анализа рисков находят все более широкое применение в различных сферах жизнедеятельности. Применительно к техносфере, наиболее развиты системы оценки рисков так называемых «опасных» объектов, к 
которым относятся, например, атомные электростанции, нефтехранилища, газопроводы, агрегаты и т.п. До недавнего времени анализ рисков не применялся в отечественной практике для оценки и управления техническим состоянием автодорожных мостовых сооружений (MC). Однако, на основе многолетнего опыта эксплуатации, существует сложившееся научное и общественное мнение о значительной потенциальной опасности участков магистралей, проходящих по МС в сравнении с проходящими по земляному полотну или выемке. Тяжесть последствий отказов при обрушениях МС весьма значительна. Обрушения МС приводят к гибели людей, транспортных средств, долговременным перерывам в движении, большим экономическим потерям, загрязнению окружающей среды, в частности водотоков.

За рубежом, в связи с пониманием потенциальной опасности $\mathrm{MC}$, в некоторых развитых странах уже давно производится соответствующий анализ рисков. Например, используют для гражданского строительства метод AMDEC с целью осуществления оценки и управления рисками. В области МС, где конструкции и технологии часто являются уникальными, метод AMDEC, по мнению ведущих специалистов, обеспечивает наибольшую объективность оценки рисков и позволяет осуществить оптимизацию управления рисками. Так, например, была разработана эффективная система, так называемая «Structural health monitoring system» (SHMS) для уникального вантового моста «Рион-Антирион» в Греции.

Ключевые слова: дорожное строительство, мостовые сооружения, риски обрушения, элементы мостовых сооружений.

Наступление нежелательных последствий, связанных с рисками эксплуатации МС возникает, как правило, при отказе: отдельного элемента; группы элементов сооружения; всего сооружения в целом. В соответствии с положениями ГОСТ Р 51901.1-2002. (Менеджмент риска. Анализ риска технологических систем) «задачей управления рисками является контроль, предотвращение или сокращение гибели людей, снижение ущерба, урона имуществу и логически вытекающих потерь, а также предотвращение неблагоприятного воздействия на окружающую среду».

Комплекс мероприятий по анализу и управлению рисками МС позволяет предотвратить или снизить тяжесть возникновения нежелательных последствий и должен включать:

- этап идентификации и декомпозиции (разбивки) МС на макроэлементы;

- этап идентификации потенциальных опасностей;

- этап прогнозирования возможных нежелательных последствий;

- этап количественной оценки критичности рисков с формированием системы балльных оценок и матрицы рисков;

- этап ранжирования элементов и разработки перечня мероприятий по управлению рисками, в том числе, путем реализации системы мониторинга инженерных конструкций.

Идентификация МС и его элементов выполняется способом декомпозиции (разбивки) МС на макроэлементы, учитывающим не только прямую тяжесть последствий головных событий, но и опосредованную - для различных типов конструкций первоначальных базовых событий и событий-следствий.

Основными критериями выделения макроэлементов в группы являются: одинаковая тяжесть последствий и вероятность наступления их частичных и полных отказов, зависящие от пространственного положения, размеров и конфигурации, типов конструкционных материалов и грунтов оснований, расположения в зонах судоходства и аэронавигации и других подобных критериев, влияющих на степень (критичность) риска. Исходное техническое состояние макроэлементов при анализе рисков на данном этапе принимается для новых объектов идеальным, то есть без отклонений от норм, строительного брака, износа, старения материалов, эксплуатационных дефектов и повреждений. 
Для обеспечения эффективной и безопасной эксплуатации объекта на протяжении всего жизненного цикла рекомендуется поэтапно разработать комплексный проект содержания мостового перехода (ПСМП), откорректировав его непосредственно перед сдачей объекта в эксплуатацию по данным предпусковых испытаний и обследований с учетом строительного брака и других возможных дефектов. Как показала практика, это позволяет повысить объективность решений по управлению рисками, закладываемых в проекты содержания и откорректировать систему мониторинга. Далее, в процессе эксплуатации объекта, критичность рисков следует периодически переоценивать по данным подробных обследований с периодичностью 5-10 лет, в соответствии с изменением во времени состояния элементов объекта, окружающей среды и характеристик техносферы.

Основной задачей этапа идентификации потенциальных опасностей в соответствии с ГОСТ Р 51901.1-2002 является выявление и описание всех источников опасностей, актуальных для объекта анализа риска и возможных путей их реализации. При идентификации следует определить, какие элементы, технические устройства, технологические блоки или процессы в системе требуют более серьезного анализа и какие представляют меньший интерес с точки зрения безопасности.

Результатом идентификации опасностей являются:

- перечень нежелательных событий;

- описание источников опасности - факторов риска, условий возникновения и развития нежелательных событий;

- предварительные оценки опасности и риска.

В соответствии с ГОСТ Р 51901.1-2002 опасности для элементов мостового сооружения могут быть отнесены к следующим трем основным категориям:

- природные опасности (негативные воздействия окружающей среды, землетрясения, молния и т. Д.);

- технические опасности, источниками которых являются промышленное оборудование, технологические процессы, транспортные средства и т. П.;

- социальные опасности, связанные с воздействием человеческого фактора, источниками которых являются проектные ошибки, строительный брак, противоправные действия, вандализм, террористические акты и т. Д.

Выборка природных опасностей, в соответствии с (Безопасность в чрезвычайных ситуациях. Природные чрезвычайные ситуации. Термины и определения), приведена в таблице 1.

Таблииа 1.

\begin{tabular}{|c|c|}
\hline \multirow{3}{*}{$\begin{array}{c}\text { Опасные геологические явления и } \\
\text { процессы }\end{array}$} & Сейсмические воздействия \\
\hline & Оползневые, сдвиговые процессы в грунте \\
\hline & Осадка грунтов оснований (карст, разжижение и т.п.) \\
\hline \multirow{2}{*}{$\begin{array}{c}\text { Опасные гидрологические явления и } \\
\text { процессы }\end{array}$} & Воздействие водного потока и волн \\
\hline & Воздействие ледохода \\
\hline \multirow{3}{*}{$\begin{array}{c}\text { Опасные метеорологические явления } \\
\text { и процессы }\end{array}$} & Температурные воздействия \\
\hline & Ветровые воздействия \\
\hline & Удар молнии \\
\hline \multirow{2}{*}{$\begin{array}{c}\text { Опасные природные процессы в } \\
\text { материалах }\end{array}$} & Насыщение материалов влагой \\
\hline & Химическое воздействие среды (сульфаты, $\mathrm{CO}_{2}$ и т.п.) \\
\hline
\end{tabular}

Техногенные опасности регламентируются рядом нормативных документов: ГОСТ P 22.0.05-94 (Безопасность в чрезвычайных ситуациях. Техногенные чрезвычайные ситуации. Термины и определения), ГОСТ Р 22.0.01-94 (Безопасность в чрезвычайных ситуациях. Основные положения), ГОСТ Р 22.0.07-95 (Безопасность в чрезвычайных ситуациях. Источники техногенных чрезвычайных ситуаций. Классификация и номенклатура поражающих факторов и их параметров). Для МС актуален следующий перечень техногенных опасностей (факторов риска):

- выщелачивание и карбонизация бетона; 
- накопление хлоридов в бетоне;

- коррозия металла;

- потери предварительного напряжения (натяжения);

- воздействие переменных нагрузок (усталость);

- воздействие сверхнормативных нагрузок;

- удар автодорожного транспортного средства;

- навал судна;

- удар самолета;

- возгорание транспортных средств на проезжей части;

В контексте настоящего анализа рисков объектом социальных опасностей является мостовое сооружение, а человек может пострадать опосредованно, например, при разрушении мостового сооружения получить ранения или погибнуть; понести экономический ущерб в составе социума, а также индивидуально, получив повреждения или утрату транспортного средства, опоздав к месту назначения, понеся издержки и т.д.

Весь спектр опасностей социального происхождения для мостового сооружения можно подразделить на две группы:

- умышленные противоправные действия: терроризм, вандализм;

- производственные ошибки жизненного цикла, брак

Опасность дефектов проектирования и строительства (при их наличии) может быть очень высока, а вероятность, как правило, мала из-за наличия высокого технического уровня организации-проектировщика и привлечения большого количества экспертных и контролирующих органов.

Практика показывает, что наименее предсказуем, в смысле роста нежелательных последствий, наиболее длительный период жизненного цикла моста - эксплуатация, включающий такие производственные процессы, как надзор, содержание, ремонт и реконструкция. Негативными последствиями производственных ошибок на протяжении всего жизненного цикла могут быть практически любые отклонения от нормативной работы сооружения, вплоть до критических отказов и обрушений.

Наиболее эффективными организационными мероприятиями по снижению степени риска производственных ошибок проектирования, строительства и эксплуатации являются: экспертиза, авторский надзор, строительный контроль, разработка проекта эксплуатации моста, надзор при эксплуатации, контроль качества содержания.

\section{Заключение.}

Выявив все наиболее часто встречаемые источники опасностей, актуальные для объекта анализа риска, можно сделать вывод, что существует три основных категории опасностей - природные, техногенные и социальные.

Последствия обрушения мостов всегда сопряжены с решением комплекса проблем: транспортной доступности территории, транзита грузов и пассажиров, восстановлением или строительством новой переправы, что в условиях РФ дорого и зачастую небыстро. В связи с чем, анализ рисков для оценки и управления техническим состоянием автодорожных мостовых сооружений является наиболее

$$
\text { *** }
$$

1. Методическое руководство по сбору и обновлению информации о мостах для ИПС «Мост» / Москва: ГипродорНИИ: ЦБНТИ Минавтодора РСФСР, 1981 - С 43.

2. Пассек В.В. Обрушения мостовых конструкций за рубежом: учебное пособие / В.В. Пассек; - Москва: б.и.., 1970. С. 27.

3. Ежелева Л.Н. Мост безопасности // Строительство и городское хозяйство - 2016 - № 169 С. 17-19.

4. Яшнов А.Н., Рыбалов А.Ю. Оценка технического состояния мостовых сооружений в системе мониторинга // Дороги - 2013 - №72 С 9-11.

5. Нигаматова О.И., Смердов Д.Н. К вопросу оценки технического состояния автодорожных мостовых сооружений // Инновационный транспорт - 2013 - №4 - С 26-28. 